\title{
Cluster and Principal Component Analysis of Semi-Dwarf Tef [Eragrostis tef (Zucc.) Trotter] Recombinant Inbred Lines with Emphasis to Lodging
}

\author{
Getahun Bekana \\ Ethiopian Institute of Agricultural Research, Holeta Agricultural Research Center, Holeta, Ethiopia
}

Email address:

getahunbekana2006@gmail.com, getahunbekana@yahoo.com

\section{To cite this article:}

Getahun Bekana. Cluster and Principal Component Analysis of Semi-Dwarf Tef [Eragrostis tef (Zucc.) Trotter] Recombinant Inbred Lines with Emphasis to Lodging. American Journal of Biomedical and Life Sciences. Vol. 9, No. 4, 2021, pp. 182-189.

doi: 10.11648 /j.ajbls.20210904.12

Received: August 10, 2021; Accepted: August 21, 2021; Published: August 27, 2021

\begin{abstract}
Tef is the main cereal crop widely produced and consumed in Ethiopia and preferred by millions of local smallholder farmers. It also gained recognition as a food crop in other parts of the world very recently due to its gluten-free grains and its nutritive value. Lodging is the major factor which greatly reduces both yields and quality of tef grain as well as the straw. The current study was conducted to group the lines as their similarities and assess the magnitude of genetic distances among them; then identify the contribution of individual traits for total variations. A total of 49 lines were evaluated for 16 traits using simple lattice design at Holetta and Debre Zeit in 2017 main rainy season. All the traits evaluated over the locations showed highly significant differences among the lines except fertile tiller per plant, while the lines $\mathrm{x}$ location interaction effect was highly significant for most of the traits evaluated. Cluster analysis grouped the lines into four clusters based on their similarity. The highest inter-cluster distance noted between clusters two and four while the lowest was between clusters one and four. Principal component analysis showed that about $77.6 \%$ of the gross variance among lines explained by five Principal components with eigenvalues greater than unity. This study revealed that four recombinant inbred lines had higher yield than local and standard checks. RIL\# 14 showed highest grain yield, low lodging index and other desirable traits than all lines, which could base and strengthen future tef breeding if incorporated as plant material; especially for lodging problem.
\end{abstract}

Keywords: Cluster, Genetic Distance, Inbred Lines, Principal Component, Traits

\section{Introduction}

Tef [Eragrostis tef (Zucc.) Trotter] belongs to the family Poaceae, subfamily Chloridoideae, genus Eragrostis with binomial nomenclature of Eragrostis tef (Zucc.) Trotter. It is an allotetraploid $(2 n=4 X=40)$, self-pollinated with bisexual florets of chasmogamous pollination behavior, and $\mathrm{C}_{4}$ plant $[1,2]$. Its center of origin and diversity is in Ethiopia [3]. Fifty-four of the 350 Eragrostis species, including the 14 endemic species were found in Ethiopia where they believed to been domesticated by pre-Semitic inhabitants between 4000 and $1000 \mathrm{BC}$ [4-6].

Tef is the main cereal crop widely produced and consumed in Ethiopia and favored by millions of local smallholder farmers [7]. In terms of area of cultivation, it is the leading cereal crop followed by maize and wheat. According to the
Central Statistical Agency [8], the area covered by tef during the $2019 / 2020$ cropping season was over 3.1 million hectares or $30 \%$ of the total area occupied by cereals in the country.

Despite being a staple food for many people in Ethiopia for centuries, tef has gained prominence as a food crop in other parts of the world very recently. This interest is mainly associated with its gluten-free grains and its nutritive value that is generally comparable with other common cereals [912]. However, it is also growing as a pasture crop in several countries [13]. The straw from tef is a valuable source of livestock feed because it is more palatable and nutritious than that from wheat and barley [14].

Tef is a highly versatile crop with respect to adaptation to different agro-ecologies being widely grown from sea level up to 2800 m.a.s.l. with reasonable resilience to both drought and water logging [13]. The national average yield of tef is 
about 1.85 ton per hectare [8], but it has a potential of yielding four to five tons of grain per hectare if the lodging problem is resolved [15]. The major yield limiting factors are lack of cultivars that are tolerant to lodging and shortage of improved varieties [16].

Besides, the grains are also often lost in the harvesting and threshing process because of their minute size and traditional cultural practices [17]. Tef possesses tall, weak stems that easily succumb to lodging due to wind or rain. In addition, lodging hinders the use of high input husbandry practices since the application of increased amounts of nitrogen fertilizer to boost the yield results in severe lodging [16].

Mostly lodging greatly reduces both yields and quality of the grain as well as the straw. It is reported to decrease tef grain yield by approximately 15 to $45 \%$ depending on the weather condition and inherent nature of the variety used [18]; it also hampers both manual and mechanical harvesting [16]. Using lower seed rates and late sowing dates relatively decreases the problem of lodging. Although, various attempts have been made by the research community to develop lodging-resistant tef cultivars [13, 19], no cultivar with reasonable lodging resistance has been obtained to-date except a novel tef mutant named kegne, and GA-10-3 which have a semi-dwarf phenotype, resulting in increased lodging tolerance [20].

The tef germplasm accessions showed wide genetic variability in phonological, morphological and agronomical traits $[9,13,22]$. In spite of this, there has been lack of sufficient variability in the tef germplasm for some valuable traits such as lodging and shattering resistance. Since recent past, a chemical mutagen, ethyl methane sulphonate (EMS), has been successfully utilized to induce semi-dwarf tef variants with lodging resistance as well as tolerance to aluminum toxicity and other acidity-related soil fertility problems [23-25]. The first semi-dwarf lodging-tolerant tef line, called kegne developed from an ethyl methane sulphonate-mutagenized population [20].

Some important works have also reported based on morphological, molecular and biochemical markers. According to Tareke [26], many efforts made in the past to implement different techniques and tools in order to improve tef. Some of them are such as inter-specific crossing that made between tef (Eragrostis tef) and Eragrostis curvula in an attempt to transfer the lodging tolerant trait of Eragrostis curvula to tef. However, so far, no viable hybrid obtained from the crosses. Some efforts also made to develop double haploids using gynogenesis technique and some promising tef lines were obtain [27]. The variations noted in panicle length $(14-65 \mathrm{~cm})$, culm length $(11-82 \mathrm{~cm})$, plant height $(31-$ $155 \mathrm{~cm})$, culm thickness $(1.2-4.5 \mathrm{~mm})$ all indicate the potential for developing lodging-resistant genotypes through gene re-combination as suggested by [4].

Through many struggles made till now almost 51 improved varieties were released to the farming communities [28]. However, development of high yielding and lodging tolerant tef varieties, adapting to the changing climate remains to be the primary focus of tef research $[29,30]$.
Especially, semi-dwarf tef types did not studied much yet and there is no lodging resistant tef [31]. Therefore, the current study conducted with the following objectives.

Objective: -

1) To classify the lines based on their similarities and determine the level of genetic divergence among the clusters.

2) To identify major traits that contribute to the overall genetic variability among semi-dwarf tef lines to emphasize on these traits in further tef breeding.

\section{Materials and Methods}

\subsection{Descriptions of Experimental Locations}

The field experiment was carried out at two locations (Debre Zeit and Holetta) in the central parts of Ethiopia during the 2017 cropping season (July to December). Debre Zeit is located at $47 \mathrm{~km}$ to south east of Addis Ababa, while Holetta is located at $42 \mathrm{~km}$ to the west of Addis Ababa. DZARC found at $\left(8^{\circ} 44^{\prime} \mathrm{N}, 38^{\circ} 58^{\prime} \mathrm{E}\right.$ and 1860 m.a.s.l) whereas, HARC found at $\left(9^{\circ} 03^{\prime} \mathrm{N}, 38^{\circ} 30^{\prime} \mathrm{E}\right.$ and 2400 m.a.s.l) latitude, longitude and altitude, respectively. The two locations represent two different agro-ecologies of the country. Debre Zeit receives mean annual rainfall of $832 \mathrm{~mm}$ during the main growing season with maximum and minimum mean annual temperature of $24.3^{\circ} \mathrm{C}$ and $8.9^{\circ} \mathrm{C}$, respectively. The experimental field at Debre Zeit characterized by heavy black soil (Vertisol) with a $\mathrm{pH}$ of 6.9 and described as very fine montmorillonitic typic pellustert with very high moisture retention capacity $[32,33]$.

In contrast, Holeta often receives annual total rainfall 1100 $\mathrm{mm}$ with maximum and minimum mean annual temperature of $24.1^{\circ} \mathrm{C}$ and $6.6^{\circ} \mathrm{C}$, respectively. The experimental field at this location characterize by light red soil (Andosol) with a $\mathrm{pH}$ of 6.3 and good moisture holding capacity. The weather conditions during the growing season were favorable and the experiment received sufficient amount of rainfall for normal growth of tef crop at each of the test locations.

\subsection{Planting Materials}

These experimental plant materials comprised 49 semidwarf tef recombinant inbred lines including local and standard checks. These included 45 recombinant inbred lines (RIL) derived from the crosses of DZ-01-192 x GA-10-3, the two parents (pure lines), one standard and local check (Table 1).

The RILs are descendants of the intra-specific cross through continuous maintenance of progenies up to the seventh filial generation (F7) through selfing using F2derived single-seed-decent breeding method. The tef cultivar DZ-01-192 is late maturing, thick culmed, tall, has loose panicle and white seed color. GA-10-3 is a mutant line developed through mutation breeding by using Ethyl methane sulphonate (EMS) assisted by Targeted Induced Local Lesions IN Genomes (TILLING) method and introduced from university of Bern (Switzerland). It has 
lodging tolerance characters, early maturity, semi-dwarf structure and pale white seed color. The materials kindly supplied by Debre Zeit agricultural research center, in
Ethiopia. I have duly acknowledged DZARC for their kindness.

Table 1. Experimental materials.

\begin{tabular}{|c|c|c|c|}
\hline No. & Recombinant Inbred Lines SD-Tef & No. & Recombinant Inbred Lines SD-Tef \\
\hline 1 & DZ-01-192 x GA-10-3 (RIL \# 1) & 26 & DZ-01-192 x GA-10-3 (RIL \# 58) \\
\hline 2 & DZ-01-192 x GA-10-3 (RIL \# 2) & 27 & DZ-01-192 x GA-10-3 (RIL \# 68) \\
\hline 3 & DZ-01-192 x GA-10-3 (RIL \# 4) & 28 & DZ-01-192 x GA-10-3 (RIL \# 75) \\
\hline 4 & DZ-01-192 x GA-10-3 (RIL \# 5) & 29 & DZ-01-192 x GA-10-3 (RIL \# 160) \\
\hline 5 & DZ-01-192 x GA-10-3 (RIL \# 6) & 30 & DZ-01-192 x GA-10-3 (RIL \# 161) \\
\hline 6 & DZ-01-192 x GA-10-3 (RIL \# 8) & 31 & DZ-01-192 x GA-10-3 (RIL \# 162) \\
\hline 7 & DZ-01-192 x GA-10-3 (RIL \# 12) & 32 & DZ-01-192 x GA-10-3 (RIL \# 166) \\
\hline 8 & DZ-01-192 x GA-10-3 (RIL \# 14) & 33 & DZ-01-192 x GA-10-3 (RIL \# 169) \\
\hline 9 & DZ-01-192 x GA-10-3 (RIL \# 15) & 34 & DZ-01-192 x GA-10-3 (RIL \# 171) \\
\hline 10 & DZ-01-192 x GA-10-3 (RIL \# 16) & 35 & DZ-01-192 x GA-10-3 (RIL \# 172) \\
\hline 11 & DZ-01-192 x GA-10-3 (RIL \# 19) & 36 & DZ-01-192 x GA-10-3 (RIL \# 174) \\
\hline 12 & DZ-01-192 x GA-10-3 (RIL \# 20) & 37 & DZ-01-192 x GA-10-3 (RIL \# 175) \\
\hline 13 & DZ-01-192 x GA-10-3 (RIL \# 21) & 38 & DZ-01-192 x GA-10-3 (RIL\# 178) \\
\hline 14 & DZ-01-192 x GA-10-3 (RIL \# 22) & 39 & DZ-01-192 x GA-10-3 (RIL \# 179) \\
\hline 15 & DZ-01-192 x GA-10-3 (RIL \# 24) & 40 & DZ-01-192 x GA-10-3 (RIL \# 180) \\
\hline 16 & DZ-01-192 x GA-10-3 (RIL \# 25) & 41 & DZ-01-192 x GA-10-3 (RIL \# 182) \\
\hline 17 & DZ-01-192 x GA-10-3 (RIL \# 27) & 42 & DZ-01-192 x GA-10-3 (RIL \# 185) \\
\hline 18 & DZ-01-192 x GA-10-3 (RIL \# 28) & 43 & DZ-01-192 x GA-10-3 (RIL \# 195) \\
\hline 19 & DZ-01-192 x GA-10-3 (RIL \# 33) & 44 & DZ-01-192 x GA-10-3 (RIL \# 203) \\
\hline 20 & DZ-01-192 x GA-10-3 (RIL \# 41) & 45 & DZ-01-192 x GA-10-3 (RIL \# 262) \\
\hline 21 & DZ-01-192 x GA-10-3 (RIL \# 44) & 46 & Boset (standard check) \\
\hline 22 & DZ-01-192 x GA-10-3 (RIL \# 45) & 47 & DZ-01-192 (parental check) \\
\hline 23 & DZ-01-192 x GA-10-3 (RIL \# 48) & 48 & GA-10-3 (parental check) \\
\hline 24 & DZ-01-192 x GA-10-3 (RIL \# 52) & 49 & Local Check \\
\hline 25 & DZ-01-192 x GA-10-3 (RIL \# 57) & & \\
\hline
\end{tabular}

*SD: - Semi-dwarf tef; DZ-01:-Debre Zeit tef cultivar released through selection; GA-10-3: - -Mutant elite tef line. Source of all material were from cross of (DZ-01-192 x GA-10-3) and $\mathrm{F}_{7}$ progeny of 2016-year gained from Debre Zeit center.

\subsection{Experimental Design, Layout and Management}

The field experiments conducted using $7 \times 7$ simple lattice designs with two replications at both locations. Each plot (1 $\mathrm{m} \times 1 \mathrm{~m}$ ) consisted of five rows of $1 \mathrm{~m}$ length with an interrow spacing of $0.2 \mathrm{~m}$. The distances are $1 \mathrm{~m}$, both between plots and incomplete blocks and $1.5 \mathrm{~m}$ between replications. The tef recombinant inbred lines allotted to plots at random within each replication. Sowing was done on 13 August, 25 July 2017 at Debre Zeit and Holetta research center, respectively. As per the research recommendations, $15 \mathrm{~kg} / \mathrm{ha}$ seed rate was used for both locations.

The fertilizer rate used for each location recommended depending on the type of soil. The fertilizers used for Holetta (light red soil) were $40 \mathrm{~kg} \mathrm{~N}, 60 \mathrm{~kg} \mathrm{P}_{2} \mathrm{O}_{5}$, and $11 \mathrm{~kg} \mathrm{~S}$ per hectare, as well as $60 \mathrm{~kg} \mathrm{~N}, 60 \mathrm{~kg} \mathrm{P}_{2} \mathrm{O}_{5}$ and $11 \mathrm{~kg} \mathrm{~S}$ per hectare for Debre Zeit (Vertisol). All NPS were applied at planting with a rate of $158 \mathrm{~kg} / \mathrm{ha}$ and the remaining urea applied at the rate of $22 \mathrm{~kg} / \mathrm{ha}$ for HARC and $65 \mathrm{~kg}$ /ha for DZARC. Half of the urea applied at sowing, while the remaining half applied at tillering. Hand weeding and other management practices were performed as required for both locations.

\subsection{Data Collected}

Data collected from sixteen quantitative traits including seven traits taken on plot basis and nine traits assessed on randomly taken five plants of tef from the central rows of each plot. For individual plant trait sampled, averages of data from the five random samples of plants per plot used for statistical analyses.

The following data taken from plot basis:

Days to heading/ panicle emergence (DH): Number of days from seedling emergence to the appearance of the tips (about $5 \mathrm{~cm}$ ) of the main shoot panicle on $50 \%$ of the plants in a plot. Note that tef panicle appears without showing the booting stage, which is unlike the other small cereals like wheat and barley, but similar to that in rice.

Days to maturity (DM): Number of days from seedling emergence to physiological maturity as judged by the change to straw color of the vegetative parts on $75 \%$ of the plants in the plot.

Grain filling period (GFP): This computed as the difference between the days to panicle emergence and that to maturity.

Above ground biomass yield (ABM): The total dry weight in kilogram of the above ground biomass per plot before threshing

Grain yield (GY): The entire plot of grains weight in kilogram after threshing and sun drying.

Harvest index (HI): The ratio of grain yield to the total biomass in percent.

Lodging index (li): lodging assessment was performed as 
suggested by Caldicott and Nuttall [34] as follows:

$$
\mathrm{l} \mathrm{i}=\frac{\text { Sum }(\mathrm{LS} * \text { Respective \%age of Area Lodged })}{5}
$$

Lodging score (LS) was recorded on a $0-5$ scale as the degree of leaning from the upright position and whereby zero=completely upright non-lodged plants and five $=$ completely flat on the ground. The severity of lodging for each degree assessed as the proportion in percent of plants in a plot manifesting each degree of lodging. Finally, the lodging index for each plot was computed as the average of the product sum of each degree of lodging and the corresponding severity as indicated in the formula above.

The following observations recorded based on measurements made on five randomly taken and pre-tagged plants from the three central rows of each plots.

Plant height $(\mathrm{PH})$ : - The length of the plant in centimeter from ground level to the tip of the panicle.

Panicle length (PL): - The length in centimeter from the node where the first panicle branch starts to the tip of the panicle.

Culm length (CL): - The length in centimeter from ground level to the node where the first panicle branch starts.

Peduncle length (PDL): - The length in centimeter of the top most culm internode spanning from the last culm node until the start of the first panicle branch. It stretches from the node where the flag leaf starts to where the first panicle branch starts.

Second basal culm internode length (SCIL):

The length in centimeter of the second basal culm internode.

Second basal culm diameter (SCID): The diameter in millimeter of the second basal culm internode measured using caliper.

Fertile tiller number per plant (NFT): - Counts of the panicle-bearing tillers of pre tagged main plants that have produced a fertile panicle.

Numbers of branches per main panicle (NBP): - Counts of the total number of branches per main panicle from bottom to top.

Number of spikelets per panicle (NSP): - It is the number of spikelets counted on the panicle.

\subsection{Cluster and Distance Analyses}

Cluster analysis used to group genotypes into homogenous sets based on their response to the environments considered [33]. Hierarchical cluster analysis approach used to examine the assembling pattern of the 49-tef lines based on their similarity with respect to the corresponding means of all the 15 traits studied. A cluster analysis done to group the tested tef genotypes into genetically distinct classes using SAS Statistical Software Version 9.3 [35], following the average linkage cluster analysis. The numbers of clusters were determined based on the Pseudo-F and Pseudo- $\mathrm{t}^{2}$ options resulted from SAS procedure of cluster data analysis. The dendrogram constructed based on the complete linkage and
Euclidean distance used as a measure of dissimilarity.

Genetic distances between clusters as standardized were calculated using Mahalanobis's $\mathrm{D}^{2}$ statistics [36] as D2ij = $(x i-x j)^{\prime} \operatorname{cov}-1(x i-x j)$, where $\mathrm{D}^{2} \mathrm{ij}=$ the distance between cases $\mathrm{i}$ and $\mathrm{j}, \mathrm{x}_{\mathrm{i}}$ and $\mathrm{x}_{\mathrm{j}}=$ vectors of the values of the variables for cases $i$ and $j$ and cov- $1=$ the pooled within groups' variance-covariance matrix. The $\mathrm{D}^{2}$ values come from pairs of clusters were considered as the calculated values of Chi-square $\left(\mathrm{X}^{2}\right)$ and tested for significance both at $1 \%$ and $5 \%$ probability levels against the tabulated value of $\mathrm{X}^{2}$ for ' $\mathrm{P}$ ' degree of freedom, where $\mathrm{P}$ is the number of traits considered [37].

\subsection{Principal Component Analysis}

Principal component analysis done using Minitab Statistical software, release 17 for windows (Minitab, 2007) to identify the traits that contributed to the large part of the total variation among the genotypes [38]. In principal component analysis, eigenvalues greater than one were considered important to explain the observed variability.

\section{Results and Discussions}

\subsection{Cluster Analysis}

Cluster analysis grouped the 49 semi-dwarf tef lines into four clusters based on their mean values and similarity by using SAS version 9.3 average linkage clustering methods (Figure 1). The number of clusters determined based on the pseudo-F and $\mathrm{t}^{2}$ values, such that the pseudo-F reaches its pick and at the same time, it is larger than values before and after it in the list, while the pseudo $t^{2}$ is being at its minimum then followed by large numbers. This classified the test materials into four real clusters at about $75 \%$ level of similarity that able to classified further. The numbers of lines in each cluster varied from nineteen in cluster one; fifteen in cluster two, thirteen in cluster three and only two in the last cluster four (Table 2). The different lines grouped with in each clusters assumed more closely related in terms of the studied traits than those lines grouped into different clusters.

Cluster four had higher mean values for days to heading, days to maturity, grain filling period, plant height, panicle length, culm length, second basal culm internode length, above ground biomass, grain yield and harvest index when compared to the other clusters. In contrast to this, cluster two consisted of lines, which had the lower values for traits such as days to maturity, grain filling period, plant height, culm length, peduncle length; second basal culm internode length, above ground biomass, grain yield and lodging index (Table 2). Lines in cluster two were the earliest, the shortest in plant height, culm length, and second culm internode lengths and peduncle length and the least yielding ones in grain and biomass.

The current cluster analysis indicated that the variability presented in 49 semi-dwarf tef recombinant inbred lines were similar to earlier studies of Habte [39], who grouped 21 tef varieties and landraces into four clusters at about $60 \%$ 
similarity in that more in line with Temesgen [40] report showed four and six clusters based on 14 traits from 144 heterogeneous germplasm populations using data obtained at Holetta and Ginchi, respectively and that of three clusters reported by Costanza [41] using 39 accessions. It is also in agreement with Tadesse [17] which formed six major clusters from 35 cultivars, the others report also showed six main clusters at $75 \%$ similarity from 36 tef germplasm populations $[21,42]$.

Table 2. Mean values for traits of the four clusters of tef lines Evaluated at HARC and DZARC.

\begin{tabular}{|c|c|c|c|c|}
\hline \multirow{2}{*}{ Traits } & \multicolumn{4}{|l|}{ Clusters } \\
\hline & $\mathrm{C}_{1}$ & $\mathbf{C}_{2}$ & $\mathbf{C}_{3}$ & $\mathrm{C}_{4}$ \\
\hline Days to heading & 52.12 & 54.13 & 56.62 & 58.50 \\
\hline Days to maturity & 104.64 & 104.62 & 109.73 & 113.38 \\
\hline Grain filling period (days) & 52.53 & 50.48 & 53.12 & 54.88 \\
\hline Plant height $(\mathrm{cm})$ & 96.36 & 90.07 & 101.35 & 109.05 \\
\hline Panicle length $(\mathrm{cm})$ & 34.85 & 35.18 & 37.83 & 41.10 \\
\hline Culm length $(\mathrm{cm})$ & 61.51 & 54.89 & 63.53 & 67.95 \\
\hline Second culm internode length $(\mathrm{cm})$ & 10.51 & 9.79 & 10.89 & 10.88 \\
\hline Second culm internode diameter $(\mathrm{mm})$ & 1.77 & 1.80 & 1.84 & 2.00 \\
\hline No of Branches per main panicle & 25.82 & 25.84 & 25.87 & 24.70 \\
\hline No Spikelets per main panicles & 435.07 & 440.95 & 460.29 & 428.18 \\
\hline Above ground biomass (kg/ha) & 6702.10 & 5091.23 & 8238.26 & 9670.18 \\
\hline Grain yield (kg/ha) & 1540.52 & 1236.75 & 1850.15 & 2406.71 \\
\hline Harvest index (\%) & 24.06 & 24.75 & 22.82 & 24.81 \\
\hline
\end{tabular}

\subsection{Inter-Cluster Distance Analysis}

The highest inter cluster distance was measured between clusters two and four while the lowest one was measured between clusters one and three (Table 3). Genetic improvement through hybridization and selection depends on the extent of variability among the lines. Crossing for desirable traits can be successful between clusters with the highest and the lowest inter cluster distance.

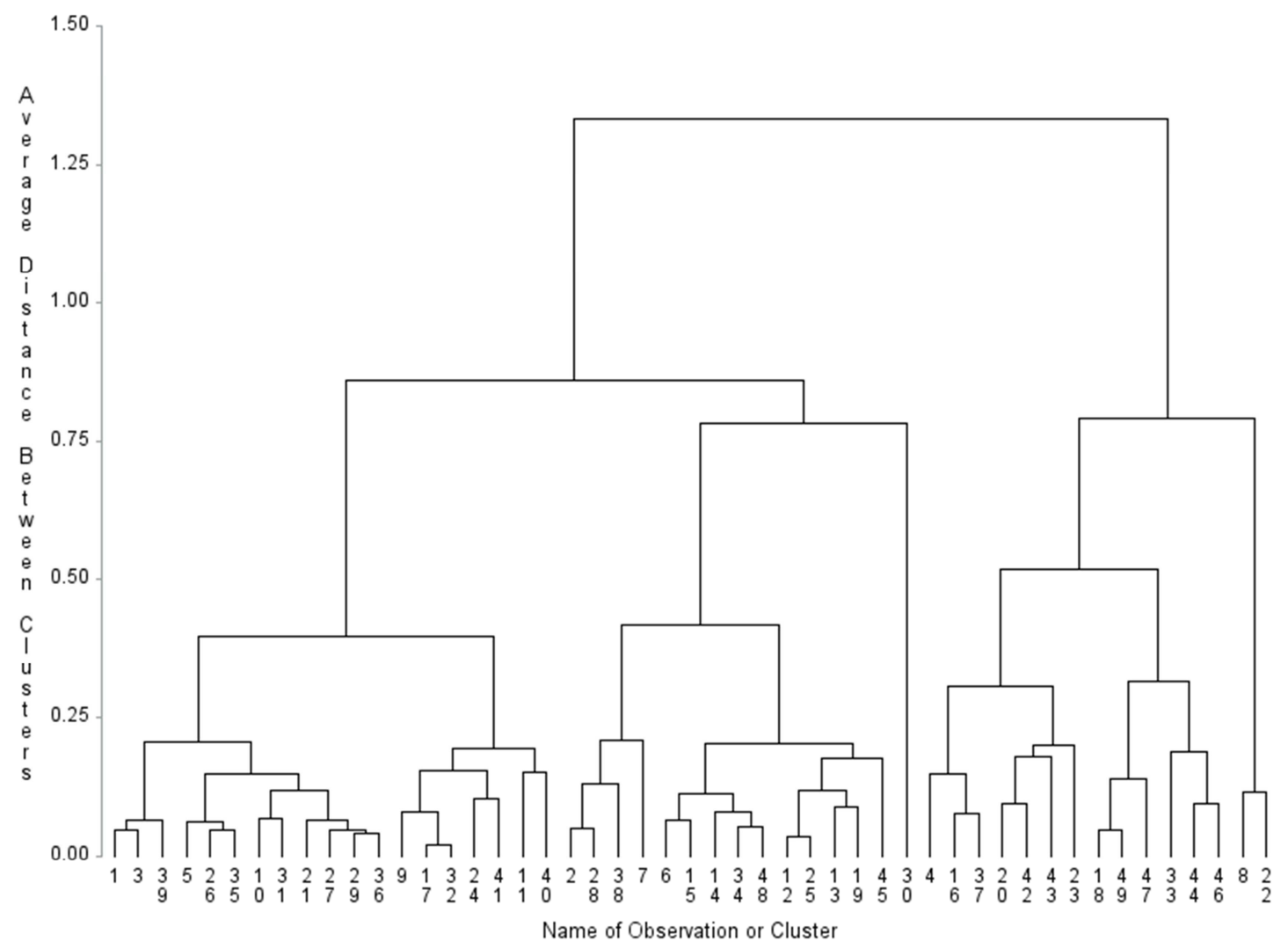

Figure 1. Dendrogram showing relationship among 49 semi-dwarf tef lines based on average linkage and Euclidean distance using the mean of 15 quantitative traits. 
Table 3. Pair wise generalized squared distances $\left(D^{2}\right)$ values between clusters constituting 49 semi-dwarf tef lines.

\begin{tabular}{llll}
\hline & Cluster1 & Cluster2 & Cluster3 \\
\hline Cluster2 & $21.75 \mathrm{~ns}$ & & \\
Cluster3 & $13.93 \mathrm{~ns}$ & $52.90 * *$ & $108.87 * *$ \\
Cluster4 & $52.77 * *$ & $20.67 \mathrm{~ns}$ & \\
\hline
\end{tabular}

* Significant at $<0.05$ for $\mathrm{x}^{2}=23.68$; $* *$ significant at $\mathrm{p}<0.01$ for $\mathrm{x}^{2}=29.14$ and $\mathrm{ns}=$ non-significant

\subsection{Principal Component Analysis}

In the principal component analysis (PCA), to estimate the relative contribution of traits towards the variation in the 49 tef lines, $77.6 \%$ explained by the first five PCs with eigenvalues greater than one out of the fifteen PCs employed for all the 15 traits. Therefore, five PCs retained to explain the observed variation without losing a substantial variability explained (Table 4).

The first PC explained about $34 \%$, the second $14 \%$, and the third $11.7 \%$, the fourth $10.9 \%$ and the fifth $6.9 \%$ of the variation. Plant height, culm length, above ground biomass and panicle length showed greater loadings on the first PC. Similarly, grain filling period, harvest index, lodging index and grain yield contributed in the second PC; while days to heading and number of spikelets per main panicle were have significant load in the third PC. In the fourth PC, days to maturity was the important trait, while in the fifth PC, number of spikelets per main panicle, lodging index and above ground biomass accounted for much of the observed gross variation.

The percentage contribution of the first five principal components to gross genetic variation obtained in the current study $(77.6 \%)$ is different from Kebebew et al [43] $81 \%$ and Temsgen et al [44] $80.6 \%$, while it is far greater than Kebebew et al [45] 71\%. This indicates that the variation depends on the type of material used in the study. There was a sharp decline in contribution from PC1 to PC2 and then from $\mathrm{PC} 2$ to $\mathrm{PC} 3$ in that order while the rate of decrease in contribution became lower and lower for the remaining PCs. This shows that the first few principal components had the greatest contribution to the overall variation in the lines and for the 15 traits considered in this study.

Table 4. Eigenvectors, eigenvalues and percentage of total variance explained by the first six principal components (PC) for 16 traits.

\begin{tabular}{|c|c|c|c|c|c|}
\hline Traits & PC1 & PC2 & PC3 & PC4 & PC5 \\
\hline Days to Heading (days) & 0.200 & -0.428 & 0.354 & 0.157 & -0.063 \\
\hline Days to Maturity (days) & 0.317 & 0.166 & 0.215 & 0.349 & -0.131 \\
\hline Grain Filling Period (days) & 0.154 & 0.511 & -0.071 & 0.221 & -0.080 \\
\hline Plant Height (cm) & 0.411 & -0.067 & -0.212 & -0.014 & 0.002 \\
\hline Panicle length $(\mathrm{cm})$ & 0.344 & -0.136 & -0.009 & -0.055 & -0.253 \\
\hline Culm Length (cm) & 0.380 & -0.017 & -0.290 & 0.011 & 0.144 \\
\hline Peduncle Length (cm) & 0.143 & 0.140 & -0.547 & -0.150 & 0.143 \\
\hline Second culm internode length $(\mathrm{cm})$ & 0.294 & -0.022 & -0.072 & -0.404 & 0.019 \\
\hline Second culm internode diameter (mm) & 0.256 & -0.272 & 0.188 & 0.006 & -0.103 \\
\hline No of Branches per main panicle & 0.088 & -0.207 & -0.087 & -0.529 & -0.351 \\
\hline No Spikelets per main panicles & 0.049 & -0.133 & 0.338 & -0.265 & 0.527 \\
\hline Above ground biomass (kg/ha) & 0.349 & 0.172 & 0.160 & 0.072 & 0.242 \\
\hline Grain yield (kg/ha) & 0.305 & 0.311 & 0.285 & -0.067 & -0.027 \\
\hline Harvest index (\%) & -0.074 & 0.344 & 0.254 & -0.291 & -0.539 \\
\hline Eigenvalue & 5.100 & 2.100 & 1.750 & 1.640 & 1.040 \\
\hline Proportion of variance explained (\%) & 34.000 & 14.000 & 11.700 & 10.900 & 6.900 \\
\hline Cumulative variance explained (\%) & 34.000 & 48.000 & 59.700 & 70.600 & 77.600 \\
\hline
\end{tabular}

\section{Conclusion}

The national average yield of tef is about 1.85 ton per hectare, but it has a potential of yielding four to five tons of grain per hectare if the lodging problem is resolved. Lodging substantially reduces the yields and quality of the grain as well as the straw. The variance analysis results were showed the presence of considerable variations among the 49-semidwarf tef lines almost for all the traits thereby suggesting higher chance of selecting lines for traits of interest. The results of analysis of variance allow carrying out further genetic analyses for all traits, except number of fertile tillers per plant, which was not significant.

Cluster analysis grouped the lines into four clusters based on their similarity. The highest inter-cluster distance occurred between clusters two and four while the lowest one was between clusters one and four. Principal components analysis showed that about $77.6 \%$ of the gross variance among lines laid in $\mathrm{PC}_{1}$ to $\mathrm{PC}_{5}$ and the total variance loaded largely by traits like plant height, panicle length and days to maturity.

To this end, the results revealed the existence of considerable variations for most traits of the test inbred lines, thus indicating the possibility of exploiting the variability in further tef breeding. Thus, recombinant inbred lines like RIL14 have significantly low lodging index, longer panicle, higher 
number of spikelets per panicle, as well as the highest above ground biomass and grain yield. Genotypes identified with better grain yield related traits and reasonable lodging tolerance require further evaluation and eventual release to the farming communities in tef growing environments in Ethiopia.

\section{References}

[1] Stallknecht, G. F., Gilbertson, K. M. and Eckhoff, J. L., 1993. Teff: Food crop for humans and animals. New crops. Wiley, New York, 5, 231-234.

[2] Yu, J. K., Kantety, R. V., Graznak, E., Benscher, D., Tefera, H. and Sorrells, M. E., 2006. A genetic linkage map for tef [Eragrostis tef (Zucc.) Trotter]. Theoretical and applied genetics, 113 (6): 1093-1102.

[3] Vavilov NI., 1951. The Origin, Variation, Immunity and Breeding of Cultivated Plants. Translated from the Russian by K. Starrchester, New York: The Ronald Press Co.

[4] Seyfu Ketema, 1993. Tef (Eragrostis tef): Breeding, Genetic Resources, Agronomy, Utilization and Role in Ethiopian Agriculture. Institute of Agricultural Research, Addis Ababa, Ethiopia.

[5] Habtamu Ayalew, Tsige Genet, Tadesse Dessalegn and Landuber Wondale, 2011. Multivariate diversity, heritability and genetic advance in tef landraces in Ethiopia. African Crop Science Journal, 19 (3): 201-212.

[6] Alganesh Tessema, 2013. Genetic Resource of Tef in Ethiopia Pp. 15-20. In: Kebebew Assefa, Solomon Chanyalew and Zarihun Tadele (eds). Achievements and Prospects of Tef Improvement. Proceedings of the Second International Workshop Debre Zeit 7-9 November 2011, Ethiopia. Ethiopian Institute of Agricultural Research, Addis Ababa, Ethiopia and Institute of Plant Sciences, University of Bern, Switzerland.

[7] Seyfu Ketema, 1997. Promoting the Conservation and Use of Underutilized and Neglected Crops, Tef (Eragrostis tef (Zucc.) Trotter). Institute of Plant Genetics and Crop Plant Research, Gatersleben/International Plant Genetic Resource Institute, Rome, Italy.

[8] CSA, 2020. Central Statistics Agency. Federal Democratic Republic of Ethiopia, Agricultural Sample Survey 2019/20 (2012 E.C.). Vol. I. Report on Area and Production of Major Crops (Private Peasant Holdings, Meher season). Statistical Bulletin 278, Addis Ababa, Ethiopia.

[9] Hailu Tefera and Seyfu Ketema, 2001. Production and importance of tef in Ethiopian Agriculture In: Hailu Tefera, Getachew Belay and Sorrells ME (eds) Workshop Proceedings Addis Ababa: Ethiopian Agricultural Research Organization 3-7.

[10] Spaenij-Dekking L, Kooy-Winkelaar Y and Koning F., 2005. The Ethiopian Cereal Tef in Celiac Disease. $N$ Engl $J$ Med 353: $1748-1749$.

[11] USDA, 2015. National Nutrient Database for Standard Reference Release, 27. United States Department of Agriculture.

[12] Cheng, A., Mayes, S., Dalle, G., Demissew, S. and Massawe, F., 2017. Diversifying crops for food and nutrition security-a case of tef. Biological Reviews, 92 (1): 188-198.

[13] Kebebew Assefa, Yu, J. K., Zeid M., Getachew Belay, Hailu Tefera, and Sorells, ME., 2011. Breeding tef [Eragrostis tef (Zucc.) trotter]: conventional and molecular approaches. Plant Breeding 130: 1-9.

[14] Alemu Yami, 2013. Tef Straw. A valuable feed resource to improve animal production and productivity. Pp. 233-251. In: Kebebew Assefa, Solomon Chanyalew and Zarihun Tadele (eds). Achievements and Prospects of Tef Improvement. Proceedings of the Second International Workshop Debre Zeit 7-9 November 2011, Ethiopia. Ethiopian Institute of Agricultural Research, Addis Ababa, Ethiopia and Institute of Plant Sciences, University of Bern, Switzerland.

[15] Yifru Tiklu and Hailu Tefera, 2005. Genetic improvement in grain yield potential and associated agronomic traits of tef (Eragrostis tef). Euphytica 141: 247-254.

[16] Kebebew Assefa, Gina Cannarozzi, Dejene Girma, Kamies Rizqah, Solomon Chanyalew, Sonia Plaza-Wuthrich, Regula Blosch, Abiel, Rendibascher, Suhaile, Refuaden and Zarihun Tadele, 2015. Genetic diversity in tef [Eragrostis tef (Zucc.) Trotter]. Front. Plant Sci. 6: 177.

[17] Tadesse Ebba, 1975. Tef (Eragrostis tef) Cultivars: Morphology and Classification. Part II. Debre Zeit Agricultural Experimental Station. Bull. No. 66 Addis Ababa University, College of Agriculture, Ethiopia.

[18] Zhu, Q., Smith, S. M., Ayele, M., Yang, L., Jogi, A., Chaluvadi, S. R. and Bennetzen, J. L., 2012, High-throughput discovery of mutations in tef semi-dwarfing genes by nextgeneration sequencing analysis. Genetics 192: 819-829.

[19] Kebebew Assefa and Zarihun Tadele, 2012. Increasing food production in Africa by boosting the productivity of understudied crops. Agronomy, 2 (4): 240-283.

[20] Jöst M., Esfeld K., Burian, A., Cannarozzi, G., Solomon, Ch., Kuhlemeier C, Kebebew, A. Zarihun, T., 2015. Semidwarfism and lodging tolerance in tef (Eragrostis tef) is linked to a mutation in the $\alpha$-Tubulin 1 gene. Journal of Experimental Botany, 66: 933-944.

[21] Kebebew Assefa, Hailu Tefera, Arnulf Merker, Turineh Kefyalew and Fufa Hundera, 2001a. Variability, heritability and genetic advance in pheno-morphic and agronomic traits of tef [Eragrostis tef (Zucc.) Trotter] germplasm from eight regions of Ethiopia. Hereditas 134: 103-101 113.

[22] Kebebew Assefa, Hailu Tefera, Arnulf Merker, Turineh Kefyalew and Fufa Hundera, 2001b. Quantitative trait diversity in tef [Eragrostis tef (Zucc.) Trotter] germplasm from Central and Northern Ethiopia. Genetic Resources and Crop Evolution 48: 53-61.

[23] Mesfin Abebe, 2007. Nature and management of acid soils in Ethiopia. M.Sc. Thesis Haramaya University, Dire Dawa, Ethiopia.

[24] Esfeld K, Plaza S, Zarihun, T. 2009. Bringing high-throughput techniques to orphan crop of Africa: highlights from tef TIILING project. Journal of Gene Conserve. 8: 803-807.

[25] Ermias Desta, Sharief Hussein, Laing, M., Fantahun Mengistu and Zarihun Tadele, 2017. Screening of ethyl methane sulphonate mutagenized tef [Eragrostis tef (Zucc.) Trotter] population identifies Al-tolerant lines. Journal of Plant Interactions, 12 (1): 170-176. 
[26] Tareke Berhe, Zewdie Gebretsadik, Edwards, S. and Hailu Araya, 2011. Boosting tef productivity using improved agronomic practices and appropriate fertilizer. Pp. 133-140. In Kebebew Assefa, Solomon Chanyalew and Zarihun Tadele (eds). Achievements and Prospects of Tef Improvement. Proceedings of the Second International Workshop Debre Zeit 7-9 November 2011, Ethiopia. Ethiopian Institute of Agricultural Research, Addis Ababa, Ethiopia and Institute of Plant Sciences, University of Bern, Switzerland.

[27] Likyelesh Gugsa, Sarial, A. K., `Lörz, H. and Kumlehn, J., 2006. Gynogenic plant regeneration from un pollinated flower explants of Eragrostis tef (Zuccagni) Trotter. Plant Cell Reports 25: 1287-1293.

[28] MoARD, 2020. Ministry of Agriculture, Plant Variety Release, Protection, and Seed Quality Control Directorate, Crop Variety Register No. 33, Addis Ababa, Ethiopia.

[29] Solomon Chanyalew, 2009. Genetic analyses of agronomic traits of tef (Eragrostis tef) genotypes. Research Journal of Agriculture and Biological Sciences, 6 (6): 912-916.

[30] Solomon Chanyalew, Kebebew Assefa and Gizaw Metaferia, 2013. Phenotypic and molecular diversity in tef. Pp. 21-31. In: Kebebew Assefa, Solomon Chanyalew and Zarihun Tadele (eds). Proceedings of the Second International Workshop Debre Zeit 7-9 November 2011; Ethiopia. Ethiopian Institute of Agricultural Research, Addis Ababa, Ethiopia, Institute of Plant Sciences, University of Bern, Switzerland.

[31] Habte Jifar, Kifle Tesfaye, Kebebew Assefa, Solomon Chanyalew and Zarihun Tadele, 2017. Semi-dwarf tef lines for high seed yield and lodging tolerance in Central Ethiopia. African Crop Science Journal, 25 (4): 419-439.

[32] Habte Jifar, Kebebew Assefa and Zarihun Tadele, 2015. Grain yield variation and association of major traits in brown seeded varieties of tef [Eragrostis tef (Zucc.) Trotter]. Agri. and Food Security 4: 7-16.

[33] Ramburan, S., Zhou, M. and Labuschagne, M. T., 2012. Investigating test site similarity, trait relations and causes of genotype $\times$ environment interactions of sugarcane in the Midlands region of South Africa. Field crops research, 129, 71-80.

[34] Caldicott, J. B. and Nuttall, A. M., 1979. A method for the assessment of lodging in cereal crops. A. Journal of Natural Institute Agricultural Botany, 15: 88-91.
[35] SAS., 2011. Statistical Analysis System, Version 9.3. SAS Institute Inc. Cary, NC, USA.

[36] Mahalanobis, P. C., 1936. On the generalized distance in statistics. Journal of National Institute of Science India, 2: 4955 .

[37] Singh, R. K. and Chaudhary, B. D. (1985). Biometrical Methods in Quantitative Genetic Analysis. Kalyani Publishers, New Delhi-Ludhiana.

[38] Garg, A. and Choudhary, V., 2012. Facial expression recognition using principal component analysis. International Journal of scientific Research Engineering and Technology, 1 (4): 39-42.

[39] Habte Jifar, 2008. Genetic Diversity and Association of Characters in Released Varieties of Tef [Eragrostis tef (Zucc.) Trotter]. M.Sc. Thesis, Addis Ababa University, Ethiopia.

[40] Temesgen Adeno, 2002. Genetic Divergence and Association of Characters among Quantitative Traits in Tef [Eragrostis tef (Zucc.) Trotter] germplasms. M.Sc. Thesis, Alemaya University, Dire Dawa, Ethiopia, 120.

[41] Costanza, S. H., J. M. J. deWet, and J. R. Harlan.; 1979. Literature review and numerical taxonomy of Eragrostis tef. Journal of Economy and Botany, 33: 413-424.

[42] Melak-Haile Mengesha, Pickett, R. C. and Davis, R. L., 1965. Genetic variability and interrelationship of characters in Teff, Eragrostis tef (Zucc.) Trotter. Crop Science journal, 5 (2): 155-157.

[43] Kebebew Assefa, Arnulf Merker and Hailu Tefera, 2003a. Multivariate analysis of diversity of tef (Eragrostis tef (Zucc.) Trotter) germplasm from western and southern Ethiopia. Hereditas 138: 228-236.

[44] Temsgen Adeno, Seyfu Ketema, Hailu Tefera., and Sridhara, H., 2005. Genetic diversity in tef [Eragrostis tef (Zucc.) Trotter] germplasms. Genetic Resource and Crop Evol. 52: 891-902.

[45] Kebebew Assefa, Seyfu Ketema, Fufa Hundera, Hailu Tefera, Turineh Kefyalew and Mulu Ayele, 1999. Diversity among germplasm lines of the Ethiopian cereal tef [Eragrostis tef (Zucc.) Trotter]. Euphytica 106: 87-97. 